\title{
«EL MEJOR RETRATO DE CADA UNO» LA MATERIALIDAD DE LA ESCRITURA EPISTOLAR EN LA SOCIEDAD HISPANA DE LOS SIGLOS XVI Y XVII*
}

por

\author{
ANTONIO CaSTILlo Gómez \\ Universidad de Alcalá
}

RESUMEN: La correspondencia escrita alcanzó una notable difusión en la sociedad bispana de los siglos XVI y XVII llegando a ser una de las prácticas de escritura más significativas y de mayor extensión social. Se trata de una cuestión puesta de manifiesto en distintos estudios, de igual modo que también son abundantes las ediciones de epistolarios. Sin embargo, en muchos de esos trabajos apenas si se ha profundizado en los significados y en las funciones de la escritura epistolar. Partiendo de algunas reflexiones previas sobre las discursos relativos a la misma, en este artículo me propongo analizar las características materiales de los testimonios epistolares, la distinción entre las cartas y los billetes, la constitución formal de ambas tipologías y las relaciones entre la condición social de las personas y dicha producción escrita (desde las gentes de letras hasta los escribientes inexpertos). En suma, de las particularidades que conlleva cada acto de escritura contemplado desde la tensión dialéctica que se establece entre las normas que lo regulan y las apropiaciones concretas en una determinada sociedad.

Palabras Clave: Escritura epistolar. Correspondencia. Siglo de Oro. Edad Moderna

\footnotetext{
* Siglas: AGN = Archivo General de la Nación, México; AGI = Archivo General de Indias, Sevilla; AGS = Archivo General de Simancas, Valladolid; AHN = Archivo Histórico Nacional, Madrid; BFZ = Biblioteca Francisco Zabálburu, Madrid; IAN/TT = Instituto dos Arquivos Nacionais/Torre do Tombo, Lisboa; IVDJ = Instituto Valencia de Don Juan, Madrid.

Parte de la investigación realizada para este artículo tiene que ver con el proyecto Cultura escrita, poder y sociedad en el Madrid de los Austrias (Comunidad de Madrid, ref. 06/009003), del que he sido responsable. Por otro lado he contado con una ayuda de movilidad del Vicerrectorado de Investigación de la Universidad de Alcalá para una estancia de un mes en el Archivo General de la Nación de México (agosto 2004).
} 
ABSTRACT: Epistolary writing reached a remarkable diffusion in Hispanic society in the sixteenth and seventeenth centuries. It was one of the most significant forms of writing, and its social extension was also extraordinary. This has been shown in a number of different studies and editions are profuse. However, in many of those works the study of the meanings and functions of this epistolary writing is extremely limited. On the basis of some previous reflections on epistolary discourse, I attempt bere to analyze the material characteristics of epistolary testimonies, the distinction between letters and billets, the formal constitution of both, and the relations between the social conditions of the people and their written production (from the literati to inexpert writers). Finally, I will address the particularities that each act of writing involved in terms of the dialectic tension between the concrete norms and their appropriation in a certain society.

KEY WORDS: Epistolary writing. Correspondence. Golden-Age Spain. Modern Age.

El mejor retrato de cada uno es aquello que escrive. El cuerpo se retrata con el pincel, el alma con la pluma.

A. VIEIRA ${ }^{1}$.

\section{A VUELTAS CON EL ESTUDIO DE LAS CARTAS}

Por mediación del conocido «Hablen cartas y callen barbas», el refranero de los siglos áureos tomó buena nota de la importancia que la escritura epistolar estaba alcanzando como uno de los instrumentos preferentes de la comunicación escrita. A fin de cuentas lo mismo que apuntaba la fecunda producción tipográfica de manuales y formularios concebidos para enseñar y encauzar el modo de escribirlas, especialmente allí donde la retórica epistolar debía reconocer y explicitar el orden social establecido. A la fortuna editorial de dicho género se suma la progresiva organización del correo a partir del contrato suscrito entre la reina Isabel y Francisco de Tassis en 1500, seguido de su nombramiento en 1506 como Correo Mayor de Castilla y de la posterior designación en 1518 de sus sobrinos Juan Bautista, Simón y Mateo de Tassis como «maestros mayores de hostes y postas y correos de nuestra casa y corte y de todos nuestros rreynos y señoríos fuera de ellos» ${ }^{2}$; así como la reglamentación del envío de la correspondencia a los dominios americanos en 1509 y la consiguiente creación del cargo de Correo Mayor de Indias en 1514, completada con la de Co-

\footnotetext{
1 Vieira, António: «Sermón de san Ignacio de Loyola, fundador de la Compañía de Jesús, padre y patriarca del autor. Predicado en Lisboa año 1669, quando aún la Iglesia le cantava el Evangelio, que se cita», en Todos sus sermones y obras diferentes... Tomo tercero. Contiene quarenta y ocho sermones de diferentes santos, Barcelona, Imprenta de María Martí, 1734, p. 9.

2 AGS, Mercedes y Privilegios, leg. 166. Se transcribe en Montáñez Matilla, María: El correo en la España de los Austrias, Madrid, CSIC, 1963, pp. 188-190.
} 
rreo Mayor de Nueva España en $1580^{3}$. Al término del siglo XVI el sistema postal de la Monarquía hispana prácticamente abrazaba todos los rincones del Imperio 4 .

Todavía más concluyentes son los datos referidos al volumen de la correspondencia escrita, oficial y privada, en dichas centurias. De un lado, es oportuno notar la manía epistolar de algunas personas. Sin ir más lejos basta con recordar las nada despreciables 6000 misivas que el conde de Tendilla escribió en el lapso de doce años, entre 1504 y 1515 , bastantes de ellas de tipo personal y muchas otras en su condición de capitán general del reino de Granadas; o las 30000 del conde de Gondomar conservadas en la Real Biblioteca ${ }^{6}$. De otro, la extensión social de dicha práctica queda acreditada por su recurrente presencia en los registros de escrituras personales: es el caso, entre otros, tanto del meticuloso apunte que hizo de alguna de su correspondencia el estudiante Girolamo da Sommaia ${ }^{7}$; como de la treintena de asientos referidos a cartas consignados en el «inventario de los papeles que se hallaron [en] el baúl» de don Guillén de Lamporte cuando fue detenido y hecho prisionero por el Santo Oficio de México en diciembre de $1642^{8}$.

En clave diacrónica, Armando Petrucci ha señalado el impulso experimentado por la correspondencia escrita a partir de los siglos XV y XVI. No sólo por la «restauración de la escritura epistolar humanística latina en formas clásicas", sino también porque "la extensión social del alfabetismo, los descubrimientos geográficos, el aumento de las actividades productivas y comerciales y la mayor movilidad de los habitantes llevaron a una auténtica explosión y circulación epistolar en las lenguas vulgares de toda Europa»9. En lo que atañe a la España de los siglos dorados su difusión debe mucho a los avances cosechados en el terreno de la alfabetización y a la mayor necesidad de comunicación desencadenada por algunas situaciones donde la escritura se hizo casi impres-

3 GOJMAN DE BACKAL, Alicia (con la colaboración de Laura Edith Bonilla): Historia del correo en México, México, Servicio Postal Mexicano, 2000, pp. 11-26.

4 ASCANDONI RIVERO, Jaime: «El correo durante el reinado de Felipe II», en Enrique Martinez Ruiz (dir), Felipe II, la ciencia y la técnica, Madrid, Parteluz, 1999, pp. 253-274.

$s$ MORENO TrujILlo, Amparo: «Registro oficial, registro personal: la dualidad de la correspondencia del Conde de Tendilla», en Carlos Sáez \& Antonio Castillo Gómez (eds.), La correspondencia en la bistoria. Modelos y prácticas de la escritura epistolar, Actas del VI Congreso Internacional de Historia de la Cultura Escrita, vol. I, Madrid, Calambur, 2002, pp. 205-230.

6 López-VIDRIero, Ma . Luisa (dir.): Catálogo de la Real Biblioteca, XIII. Correspondencia del Conde de Gondomar, I-IV, Madrid, Patrimonio Nacional, 1999-2003.

7 Diario de un estudiante de Salamanca. La crónica inédita de Girolamo da Sommaia (1603-1607), ed. Georges Haley, Salamanca, Universidad de Salamanca, 1977, pp. 214-231.

8 AGN, Inquisición, vol. 1496, Proceso contra Guillén de Lamporte, s. fol. Sobre tan singular personaje, véase el estudio de MEZA GONZÁlEZ, Javier: El laberinto de la mentira. Guillén de Lamporte y la Inquisición, México, Universidad Autónoma Metropolitana (Unidad Xochimilco), 2002 (1997).

9 Petrucci, Armando: La ciencia de la escritura. Primera lección de paleografía, Buenos Aires, FCE, 2003 (ed. original, 2002), p. 96. 
cindible, verbi gracia, las guerras, la emigración americana, los movimientos comerciales o las relaciones diplomáticas, incluso contando con las numerosas dificultades que acechaban al correo:

Con estos correos que an venido de Italia no an llegado cartas del marqués ni del señor don Françisco. Yo he [e]ntendido que es la causa auer detenido en aguas muertas un correo que las trae, él se quedó en Villafranca ayudando a poner cobro en el dinero que lleuauan las galeras que allí dieron al traués y esperando algunas en que passar ${ }^{10}$.

Qué duda cabe que estas notas dejan ver el peso de los intercambios epistolares en la sociedad hispana de los siglos XVI y XVII. No obstante, nuestro conocimiento de esta práctica de escritura aún presenta lagunas significativas y carece de parangón con la tradición de estudio desarrollada en historiografías como la francesa, anglosajona o italiana. No hace falta abordar aquí un estado de la cuestión sobre el tema para constatar que, entre nosotros, el interés dominante se ha puesto en el valor de las cartas en cuanto fuentes de información histórica, esto es, en la medida que su contenido permite profundizar en la trayectoria de ciertas personalidades o bien en los más variados asuntos políticos, económicos, religiosos o culturales. A su vez, en el terreno de la diplomática moderna, si bien existe una larga bibliografía centrada más en el análisis de las tipologías administrativas que privadas, no es menos cierto que buena parte de esos estudios se quedan en la epidermis de la descripción documental y eluden aquellas preguntas o consideraciones que permiten ahondar en el hecho de la escritura como práctica social ${ }^{11}$.

Por consiguiente, falta profundizar en los significados y funciones de la escritura epistolar, en las características materiales de dichos testimonios y en cuanto aportan en torno a los distintos niveles de competencia y cultura gráfico-textual; esto es, en las particularidades que implica cada toma de la palabra escrita contemplada desde la tensión dialéctica que se establece entre las normas epistolares y las prácticas efectivas. Si en otros trabajos anteriores me he acercado preferentemente al contenido de los discursos relativos a la materia epistolar con objeto de desvelar el rol jugado por ésta en el panorama de la

10 Carta de Cristóbal de Paz, encargado de negocios en el virreinato de Nápoles, al secretario Mateo Vázquez (Madrid, 16-III-1576). BFZ, Altamira, 136, D.15. Respecto al panorama del alfabetismo, véanse las documentadas síntesis de SOUBEYROUX, Jacques: «L'alphabétisation dans l'Espagne moderne: bilan et perspectives de recherche", Bulletin Hispanique (Burdeos), 100, 2 (1998), pp. 231-254; y VIÑAO FRAGO, Antonio: "Alfabetización y primeras letras (siglos XVI-XVII)", en Antonio Castillo Gómez (comp.), Escribir y leer en el siglo de Cervantes, Barcelona, Gedisa, 1999, pp. 39-84.

11 Incide también en esto HAYEZ, Jérôme: "Io non so scrivere a l'amicho per siloscismi". Jalons pour une lecture de la lettre marchande toscane de la fin du Moyen Âge», I Tatti Studies (Florencia), 7 (1997), p. 38. 
cultura escrita altomoderna ${ }^{12}$; esta vez quiero partir de esas reflexiones para adentrarme más específicamente en la materialidad de las cartas, en su constitución formal y gráfica, sin descuidar su relación con la «disciplina del gesto» inherente a determinadas manifestaciones culturales, entre ellas la producción de escritura ${ }^{13}$.

Antes de entrar en el meollo de la cuestión procede destacar algunos de los problemas que encierra el estudio de las cartas en la Época Moderna, no ya por la falta de documentación sino justamente por todo lo contrario. La vastedad de los testimonios conservados acarrea cierta dificultad cuando se quieren establecer categorías precisas: por un lado, porque no es tarea fácil esbozar una determinada tipología; por otro, por los sesgos que imponen las distintas políticas de conservación documental; y en tercer lugar, por los desequilibrios que ha ocasionado la hegemonía de ciertas líneas historiográficas. En este punto huelga comentar que muchas de las cartas y epistolarios rescatados y editados, cuya relación omito por innecesaria, corresponden a gobernantes, cortesanos, diplomáticos, humanistas, escritores, nobles, mujeres ilustres y hombres de negocios; mientras que, salvo excepciones, los esfuerzos han sido menores, sin dejar de haberlos, con respecto a la actividad epistolar de la gente común. Admito que tal proceder debe mucho a las múltiples circunstancias que han intervenido en la transmisión de la memoria escrita; pero esto no exonera la cuota de responsabilidad imputable a las concepciones de la historia más solícitas con el devenir de las clases dirigentes, por más que pueda sustentarse en su mayor posibilidad de acceso a la escritura. A esto se añade la desviación incorporada por cuantos estudiosos de la escritura, con algunos paleógrafos y diplomatistas a la cabeza, han prestado oídos sordos a los vestigios de las clases subalternas privilegiando el estudio de las elites y de la documentación más solemne.

\section{ENTRE LA CARTA Y EL BILLETE}

Si bien la tipología de la escritura epistolar admite tanta diversidad como los asuntos tratados, en su constitución material existe una primera distinción básica: la que se da entre las cartas y los billetes. Para entrar en ella es preciso partir de los significados dados a ambas en los vocabularios coetáneos. En el

12 Castillo GómeZ, Antonio: «"Hablen cartas y callen barbas». Escritura y sociedad en el Siglo de Oro", Historiar (Barcelona), 4 (2000), pp. 116-127; ID.: "Como o polvo e o camaleão se transforman". Modelos e práticas epistolares na Espanha Moderna», en Maria Helena C. Bastos, Maria Teresa S. Cunha \& Ana Chrystina V. Mignot (eds.), Destino das letras. História, educaşão e escrita epistolar, Passo Fundo, Universidade do Passo Fundo, 2002, pp. 13-55; e ID.: «Del tratado a la práctica. La escritura epistolar en la Época Moderna», en Carlos Sáez \& Antonio Castillo Gómez (eds.), La correspondencia en la bistoria, op. cit., 2002, pp. 79-107.

13 BURKe, Peter: «El lenguaje de los gestos en la Italia Moderna», en su libro Formas de bistoria cultural, Madrid, Alianza Editorial, 2000 (ed. original, 1997), pp. 87-106. 
Tesoro de la lengua castellana o española (1611) de Sebastián de Covarrubias, la primera tipología se define como «la mensajería que se envía al ausente por escrito en cualquier materia que sea»; como se ve, de manera bastante vaga, aludiendo a la distancia física que la desencadena y a los diversos matices de su contenido, según se tratara de cartas administrativas o personales, misivas o familiares, cartas de pago, de venta, de horro, provisiones, cartas de excomunión u otras modalidades ${ }^{14}$. Por el contrario, la definición de billete aporta algunos elementos de índole cualitativa que conciernen al tiempo de la escritura, a la inmediatez de la entrega y al secreto de la comunicación:

El papel en que se escribe algunas pocas razones de una a otra persona que asisten en el mesmo pueblo. Fue muy buena invención para comunicarse con más quietud y tratar las cosas con secreto, no fiándolas de ningún tercero ni criado, que muchas veces tuercen la razón y por eso los llaman estraga recados ${ }^{15}$.

Tales definiciones evocan la distinción material y de contenido existente entre ambos formatos epistolares. Mientras que las cartas, por lo general, se redactaban en folios o bifolios, plegados hasta obtener un cuadrado donde se anotaba el sobrescrito y se ponía el lacre; los billetes se escribían en medios pliegos, fragmentos y «pedaçicos» de papel, como los que envió el preso $\mathrm{Mi}$ guel Martínez a su mujer Catalina de Arciniega o los «dos villetes pequeños» remitidos por ella del modo siguiente:

dixo que avrá ocho días que le embió un villete en una caxa de conserua y para meterlo en secreto desfondó el suelo de la caxa y lo metió; y después le embió un cántaro de agua como se la embía de ordinario y dentro della en un canato otro villete bien tapado y un poco de tinta por que no le escriuiese con sangre, atado en una piedra para que se fuese al fondo ${ }^{16}$.

Tampoco era raro que se aprovechara el reverso de documentos inservibles así como de otras cartas y escritos varios. Por supuesto, esto no obsta para que también podamos encontrar tanto billetes con la apariencia material de la carta como misivas redactadas en pliegos de menor dimensión. Entre éstas señalo sendos ejemplares del hermano Pedro García a la madre Leonor de la Encarnación, escritas en papeles de tamaño octavo y dieciseisavo pero con toda la con-

14 Covarrubias, Sebastián de: Tesoro de la lengua castellana o española, ed. Felipe C. R. Maldonado revisada por Manuel Camarero, Madrid, Castalia, 1995, p. 278.

is Ibidem, p. 189. Esta definición sirve de referencia a la posterior del Diccionario de Autoridades (1726): «papel pequeño doblado en formas diversas, con que recíprocamente se comunica la gente en cosas de poca conseqüencia, y se evita la equivocación de los recados, tan común en los familiares». Diccionario de Autoridades, vol. I, Madrid, Gredos, 1984 (ed. facsímil), p. 189.

16 AGN, Inquisición, vol. 93, exp. 1, fol. 52v-53r. Los billetes del marido son prácticamente ilegibles por cuanto los escribió con su sangre conforme hizo notar en uno de ellos: «la tinta es mi propia sangre y la pluma es un ojo» (fols. 49-50).

Hispania, LXV/3, núm. 221 (2005) 847-876 
sistencia epistolar y su pertinente sobrescrito, del que suelen carecer los billetes ${ }^{17}$. Éstos, en cuanto escritura de la inmediatez, se usaban para transmitir informaciones urgentes o para atender las necesidades de comunicación y expresión en situaciones singularmente problemáticas, como en las cárceles ${ }^{18}$. El tejedor Francisco Anguino, procesado en 1687 por el Santo Oficio de México bajo sospecha de alumbrado, se sirvió un par de años antes de varios «papelitos» para formular algunas reflexiones y consejos espirituales al mercader José de Villalta [Fig. 1], según éste confesó al hacer entrega a los jueces inquisidores de los treces billetes que conservaba:

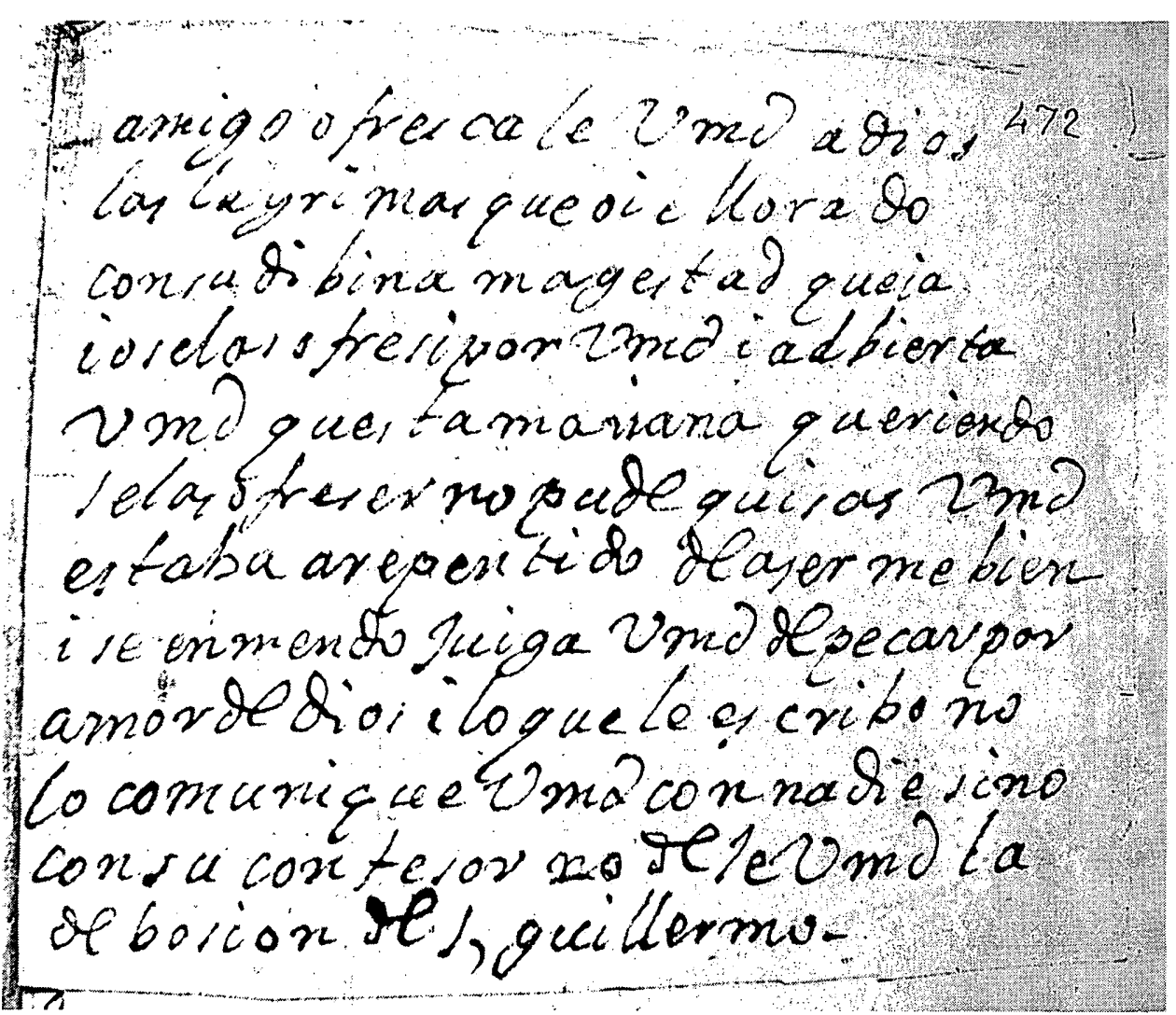

Fig. 1. Billete del tejedor Francisco Anguino al mercader José Villalta [c. 1685]. AGN, Inquisición, vol. 1551, $2^{\mathrm{a}}$ parte, exp. 31, fol. 472 r.

17 AGN, Inquisición, vol. 436, fols. 439-445.

18 Sobre este asunto remito a mi trabajo «Escrito en prisión. Las escrituras carcelarias en los siglos XVI y XVII», Península. Revista de Estudos Ibèricos (Oporto), 0 (2003), pp. 147-170; así como al capítulo IV de mi libro Entre la pluma y la pared. Una bistoria social de la escritura en los Siglos de Oro, Madrid, Akal, 2006. 
Y assimesmo declara que en el tienpo que ést $\langle e\rangle$ comunicó al dicho Françisco Anguino, el suso dicho escribió a éste treze papelitos de su letra, sin fecha ni firma, en que en todos trata y habla de cosas de espíritu, y en algunos le pide alguna limosna ${ }^{19}$.

En lo que concierne al orden discursivo, la estructura de las cartas se acomodaba más a la retórica epistolar. Ésta se renovó notablemente durante el humanismo y, en particular, a raíz de la obra De conscribendis epistolis (1522) de Erasmo, dado que los manuales anteriores habían terminado por "congelar el género epistolar en una práctica administrativa de los secretarios» ${ }^{20}$. Según se establece en dichos tratados, las partes básicas de una carta eran las siguientes:

$1^{\text {a }}$. Salutatio. Compuesta por la expresión inicial de saludo y, en su caso, por la invocación precedente en forma de cruz.

$2^{\mathrm{a}}$. Captatio benevolentiae o expressio malevolentiae. Esta fórmula servía para introducir el texto aludiendo a la relación con las cartas anteriores o a la ausencia de éstas, seguida de las expresiones de deseo concernientes a la salud del que escribe, su corresponsal y los respectivos círculos afectivos.

$3^{a}$. Narratio. Esto es, el texto propiamente dicho con todas sus argumentaciones y noticias.

$4^{\mathrm{a}}$. Petitio o captatio benevolentiae. Fórmula final mediante la cual el emisor corrobora sus buenos deseos hacia su corresponsal, familiares y amigos.

$5^{\mathrm{a}}$. Conclusio. Integrada por la data, muy a menudo sin indicación del año, la consiguiente expresión de humildad o sumisión y la suscripción autógrafa.

Una vez plegada, en el cuadrado resultante se consignaba el nombre del destinatario - que en determinadas cartas también se anotaba al pie de la primera plana-, el lugar de residencia y, eventualmente, otros datos referidos al mensajero, al coste del correo, buenos augurios e incluso la fecha de la respuesta en el caso de las correspondencias más regulares y organizadas ${ }^{21}$. De la naturaleza de los sobrescritos dan fe los ejemplos que siguen, la mayoría ajustados a la estructura habitual y alguno, como el último, más elaborado y retórico:

19 AGN, Inquisición, vol. 1551, $2^{\text {a }}$ parte, exp. 31, fol. 465r. Los billetes en los fols. 467-477.

20 GodIN, André: «Erasme: Théorie et usages de la lettre dans l'Europe moderne», en Daniel Odon Hurel (ed.), Regards sur la correspondance (de Cicéron à Armand Barbès), Cahiers du GRHIS, núm. 5, Rouen, Université de Rouen, 1996, p. 61. Para la tratadística epistolar en la alta Edad Moderna, PONTÓN, Gonzalo: Correspondencias. Los orígenes del arte epistolar en España, Madrid, Biblioteca Nueva, 2002; y MARTín BAÑOS, Pedro: El arte epistolar en el Renacimiento europeo 1400-1600, Bilbao, Universidad de Deusto, 2005. Sobre los artes dictandi medievales, veáse BOUREAU, Alain: «La norme épistolaire, une invention médiévale», en Roger Chartier (dir), La correspondance: les usages de la lettre au XIX siècle, París, Fayard, 1991, pp. 127-157; y MORENZONI, Franco: «Epistolografia e «artes dictandi»», en Guglielmo Cavallo, Claudio Leonardi \& Enrico Menestò (dirs.), Lo spazio letterario del Medievo, 1. Il Medioevo latino, vol. II. La circolazione dei testi, Roma, Salerno, 1994, pp. 443-464

${ }^{21}$ Así consta en las de Hipòlita Roís y Estefania de Requesens. Cfr. Epistolaris d'Hipòlita Roís de Liori i d'Estefania de Requesens (segle XVI), ed. de Eulalia de Ahumada Batlle, Valencia, Universitat de València, 2003, p. 43.

Hispania, LXV/3, núm. 221 (2005) 847-876 
Al muy magnífico señor Luis de Azebedo, mi señor, en la posada del señor Christóval de Azeuedo, en la calle de San Agustín, en Yndias, en la çiudad de México22.

A mi hijo Roque de Santa María, en Machuacán; a se de dar a Esteuan Rato, en México, en la calle de San Juan, mercader, para que la encamine, que está en compañía de Alonso Pérez, su hermano23.

A don Diego Tabira de Toledo, que Dios guarde, en México24.

A mi señora mujer Ysabel Álbarez, en Alcalá de Henares, en la calle Mayor, en casa de Vítor, barbero, con sangre sellada 25 .

A mi señor Antón Pérez, barbero, en el collasión de San Román, en Sebilla. Ba de la ziudad de México, de su chijo (sic) Bartolomé de Morales ${ }^{26}$.

A mi señora mujer Ana Martín, en la calle ancha de San Biçente, en el atahona grande, en Sevilla ${ }^{27}$.

A la madre Leonor de la Encarnaçión, guarde nuestro señor ${ }^{28}$.

$\dagger$ A la madre Ysabel de San Juan, guarde nuestro señor, priora en San Bernardo; y que si ubiere de abrirla despida luego al portador, que la respuesta la podrá enbiar al tienpo que adentro se berá; y si la dicha prelada no la ubiere de abrir mandará que la buelban al que la lleba para que se la entriege al señor bicario del dicho conbento29.

Por supuesto, esto no es óbice para que algunas cartas se redactaran sin tantos miramientos, como tampoco dejaron de escribirse billetes cuya consistencia material y textual guardaba bastante similitud con aquellas. Una muestra de ello la proporciona el ramillete debido a Miguel de Piedrola y Beaumont, donde también se ve la distinción gráfica según los escribiera él o su secretario, como el que comienza «Dentro de este billete ban las copias de los originales que se hallan en poder de v. m.», firmado «Piedrola» y fechado el 21 de agosto de $1587^{30}$. Los billetes, sin embargo, no solían requerir la misma formalidad textual, sino que su estructura era bastante más simple y, por lo general, carecía de algunas de las partes intrínsecas al discurso epistolar. Introducidos, llegado el caso, por una simple invocación en forma de cruz y una sencilla fórmula de saludo; seguía el texto, casi siempre breve y preciso, por lo común sin mención de la fecha ni del lugar de redacción; y se concluía con la suscripción, a menudo sustituida por una inicial o por alguna otra expresión alusiva a la relación con el corresponsal. Diego de Vítores firmó sus billetes a

\footnotetext{
22 AGN, Inquisición, vol. 135, exp. 12, fol. 404r.

23 AGN, Inquisición, vol. 368 (2), fol. 588. Las cartas en los fols. 589-590.

${ }^{24}$ AGN, Inquisición, vol. 360 (1), exp. 7, fol. 107v.

25 AHN, Inquisición, leg. 23, exp. 21, s. fol.

26 AGI, Indiferente General, leg. 2055, núm. 27, 1, fol. 18.

27 AGI, Indiferente General, leg. 2054, núm. 17, 1, fol. 6

28 AGN, Inquisición, vol. 436, fol. 440v.

29 AGN, Inquisición, vol. 436, fol. 380.

$30 \mathrm{AHN}$, Inquisición, Consejo, leg. $3712^{3}$, núm. $2,6^{\mathrm{a}}$ pieza, núm. 8 , s. fols.
} 
Lucrecia de León con una V ${ }^{31}$; mientras que la zaragozana Ana María Lagunas, descendiente de una familia de infanzones, puso "tu esclava» en alguno de los que dirigió al notario Diego Jerónimo Montaner, su futuro marido ${ }^{32}$.

Lejos de la decadencia advertida por Armando Petrucci para Italia ${ }^{33}$, la exploración efectuada en el ámbito hispano corrobora la intensidad y persistencia de esta forma epistolar a lo largo de los siglos XVI y XVII, en muchos casos asociada a la transmisión de los mensajes amorosos y con las mujeres como primeras protagonistas. Esta relación debía ser bastante notoria pues fue una de las razones esgrimidas por Juan de la Cerda para desaconsejar que ellas aprendieran a escribir:

mas el escrevir ni es necessario, ni lo querría ver en las mugeres; no porque de suyo sea malo, sino porque tienen la ocasión en las manos de escrevir villetes, y responder a los que hombres livianos les embían ${ }^{34}$.

Junto a esto, su presencia en los fondos documentales de la época constituye la cara más veraz de una práctica que goza igualmente de una extensa representación en la literatura coetánea, sobre todo en cuanto concierne al cariz amoroso de muchos de ellos. Valga para probarlo el diálogo que sigue, tomado de la comedia El pregonero de Dios y patriarca de los pobres (1684) del bachiller Francisco de Acevedo, una obra referente a la vida y obra de san Francisco de Asís que, a la sazón, fue calificada por la Inquisición de México como «muy repugnante»e «injuriosa a la seráphica santidad del glorioso patriarcha San Francisco»:

$\begin{array}{ll}\text { IRENE: } & \text { Diste el papel } \\ \text { LUCRECIA: } & \text { Sí, Señora } \\ & \text { a don Francisco en su mano } \\ & \text { y le dixe que tu hermano } \\ & \text { en casa no estaba aora, } \\ & \text { rogándole que viniesse } \\ & \text { a verte antes de las dies, } \\ & \text { sin tener cuidado pues } \\ & \text { la noche nos favorese } e^{35} .\end{array}$

31 AHN, Inquisición, leg. $115^{2}$, exp. 4.

32 NAvarro Bonilla, Diego: «Los archivos del sentimiento: función y representaciones de billetes y papeles de amor en la Edad Moderna", Pliegos de Bibliofilia (Madrid), 22 (2003), pp. 26-31; e Idem: Del corazón a la pluma. Archivos y papeles privados femeninos en la Edad Moderna, Salamanca, Ediciones Universidad de Salamanca, 2004.

33 Así lo expuso en la conferencia, aún inédita, Per uno studio grafico e materiale della comunicazione scritta. Esperienze e prospettive, pronunciada en el marco del Seminario Scrittura e comunicazione. I carteggi pubblici e privati dal Medioevo all' età contemporanea, celebrado en Prato del 8 al 13 de septiembre de 2003, organizado por el Istituto di Studi Storici Postali y el Archivio di Stato de dicha ciudad.

34 CERDA, Juan de la: Libro intitulado: Vida política de todos los estados de mugeres..., Alcalá de Henares, Juan Gracián, 1599, fol. 12v.

35 AGN, Inquisición, vol. 1508, exp. 8, fols. 169-170.

Hispania, LXV/3, núm. 221 (2005) 847-876 


\section{NI RENGLONES TUERTOS NI LETRAS TRASTOCADAS}

Los manuales y formularios epistolares avisaban del orden que las cartas debían observar para cumplir su funcionalidad social. Ésta dependía mucho del acatamiento dispensado a las reglas de ese pacto; esto es, de su adecuación a un estilo, ajenö según Gaspar de Tejeda a toda sombra de afectación ${ }^{36}$, que pasaba por comprender el propósito de cada misiva y por adaptarla a la condición del destinatario. Antonio de Torquemada lo resumió con mucho tino al señalar que quien comenzase a escribir una carta debía poner todo su entendimiento en ello y tener delante de los ojos las siguientes seis cuestiones: «Quién, A quién, Por qué, Qué, Cuándo, De qué manera» ${ }^{37}$. Emanuele Tesauro, otro de los tratadistas del género, también fue muy claro al fijar los términos en que debían escribirse las cartas según la persona a la que estuvieran dirigidas:

En quanto a la persona a quien se escrive, cierto es que con diferentes términos se escrive al señor que al súbdito o al igual. Porque al Señor se escrive con términos de sumissión, reverencia, humildad, obediencia, súplica y obsequio.

Al súbdito, con términos de autoridad y señoriles, mandando, imponiendo y mostrando voluntad de premiarle y de valerse de su servicio, diligencia y fidelidad.

A los iguales, con términos urbanos y corteses; expressivos de un cordial amor y eterna obligación a sus favores, ofrecimientos afectuosos de servirle, eficaces ruegos y otras fórmulas que en su lugar se dirán ${ }^{38}$.

Dicho respeto implicaba el conocimiento de una gramática comunicativa que era indispensable para garantizar la comprensibilidad del texto y para vincular la carta a su emisor evitando cualquier sospecha al respecto, máxime dadas las suplantaciones de autoría que solían darse en las correspondencias diplomáticas. De acuerdo a don Luis de Haro, eso fue lo que pretendió el cardenal Mazarino en las conversaciones que mantuvieron a lo largo de 1659 para firmar la paz entre España y Francia. En algunas de sus cartas alude a las

36 TEjedA, Gaspar de: Cosa nueva. Primer libro de cartas mensageras en estilo cortesano para diversos fines y propósitos, con los títulos y cortesías que se usan en todos los estados, Valladolid, Sebastián Martínez, 1553, fol. $103 \mathrm{v}$.

37 Torquemada, Antonio de: Manual de escribientes [ca. 1552], ed. Manuel Arroyo Stephens, Madrid, Turner, 1994, p. 124.

38 'TeSAURO, Emanuele: Arte de cartas misivas, o méthodo general para reducir al papel quantas materias pide el político comercio, Valencia, Jaime de Bordazar, 1696, pp. 17-18. Según ha señalado SALAMANCA LÓPEZ, Manuel: "La "forma accidental" en el Arte de cartas misivas de Emanuele Tesauro», en Carlos Sáez \& Antonio Castillo Gómez, La correspondencia en la bistoria, op. cit., p. 276, la primera edición italiana que se conoce de esta obra se imprimió en Bolonia en 1669, aunque, por lo que se desprende de los preeliminares, en concreto de la censura, debió existir otra anterior. Para distintos pormenores de la obra, véase también DOGLIO, Maria Luisa: «Lettera e "arte epistolare". L'Arte delle lettere missive di Emanuele Tesauro", en su libro L'arte delle lettere. Idea e pratica della scrittura epistolare tra Quattro e Seicento, Bolonia, Il Mulino, 2000, pp. 217-223. 
tretas empleadas por el ministro francés y, en particular, a su constante pretensión de mostrarse como amigo de los reyes de España, llegando a falsificar sus misivas con el fin de hacerlas pasar por reales:

Todas estas cartas se reconoçe manifiestamente que son dispuestas por el cardenal y embiadas en minuta para que vengan en esta conformidad porque demás de que lo da a conoçer assí todo el contenido dellas, en las del Rey hay muchas cláusulas que, por la sustançia dellas y por los términos por donde se explica y algunas otras circunstançias, se haçe mucho más manifiesto que en sus años no pueden ser suyas. Y para haçerme creer el cardenal todo lo contrario, acostumbra, quando las va leyendo, pasar quatro ô çinco renglones mal pronunçiados y, en otras partes, capítulos enteros sin leerlos, como queriendo dar â entender que son sobre materias más reserbadas que no se me pueden partiçipar, las intrínsicas de la confidençia, vsando para ello de éstas y de otras muchas apariençias semejantes en las quales no es el mayor trabaxo el oírlas sino el hauer de dar â entender que todas se creen (como yo lo hago), ponderándole mucho el gran fauor que el Rey y la Reyna le haçen y quan justamente le mereçe39.

Apunta Luis de Haro que dichas cartas contenían muchas cláusulas que no podían ser obra de Mazarino, quien para disimularlo tuvo la astucia de leerlas omitiendo aquellas expresiones que lo pudieran delatar. Mostró así la importancia asignada a las "condiciones» epistolares para que las cartas no fueran «todas de una manera, sino diferentes conforme a las diferençias que oviere entre nosotros y las personas a quien se escriven» ${ }^{40}$. Tanto la forma como el estilo permitían identificar el origen y el cometido de cada misiva a la vez que entrañaban una manera de explicitar o hacer visible el poder y la distinción. De ahí que tales formalidades fueran mayores entre corresponsales diplomáticos y en los intercambios epistolares más sujetos a las etiquetas cortesanas ${ }^{41}$. En circunstancias así no valía cualquier clase de papel o de tinta y menos aún descuidar la escritura o servirse de «letras trastocadas», conforme dio a entender Antonio de Guevara en sus Epístolas familiares al reprobar las maneras de un señor al escribir sus cartas:

Sabed, Señor, que las condiciones de vuestra carta eran ser el papel grueso; la tinta, blanca; los renglones, tuertos; las letras, trastocadas; y las razones borradas;

39 Carta de don Luis de Haro a Felipe IV (Fuenterrabía, 3-VIII-1659), AGS, Estado, Francia, K 1623: 65. Véase en MÉNDEZ DE HARO Y GuZMÁN, Don Luis: Letters from the Pyrenees. Don Luis Méndez de Haro's. Correspondence to Pbilip IV of Spain, July to November 1659, ed. Lynn Williams, Exeter, University of Exeter Press, 2000, p. 53.

40 Torquemada, Antonio de: Manual de escribientes, op. cit., p. 135

41 Sobre este asunto me remito a la obra clásica de ELÍAS, Norbert: La sociedad cortesana, México, FCE, 1982 (ed. original, 1969). Respecto a la distinción buscada por los manuales epistolares y de civilidad, CHARTIER, Roger: Libros, lecturas y lectores en la Edad Moderna, Madrid, Alianza, 1993, concretamente los capítulos 8 y 9.

Hispania, LXV/3, núm. 221 (2005) 847-876 
de manera que vos, Señor, la escrebistes a la luna, o algún niño que era aprendiz en la escuela ${ }^{42}$.

Con tanto desarreglo, la carta ni parecía suya ni podía cumplir la funcionalidad social inherente a las convenciones establecidas en los tratados epistolares. Éstos regularon el lenguaje empleado con objeto de que fuera lo menos afectado posible; pero también atendieron a la relación entre la página y el texto dictando normas sobre la importancia de los blancos, la alineación de la escritura o el módulo de la letra, que, al decir de Antonio de Torquemada, debía «ser de buen tamaño, ni muy grande ni muy pequeña, hermosa, ygual, clara, de manera que se dexe leer bien, las partes apartadas, y que sea conforme al uso del tiempo y de la tierra donde se escrive» ${ }^{43}$. En tales circunstancias se imponía casi inevitablemente la redacción previa de un borrador, según prescribían algunos textos como la Instrucción de Pietro Gaetano cuando fue a servir al príncipe de Parma Alejandro Farnesio (c. 1583):

Note brevemente en un papel las cossas que entendiere o le venieren a la memoria para escribir y haga de todo memorial, el qual tenga delante quando escribiere y vaya por los capítulos dél escribiendo la carta y vorrando en el memorial el capítulo que hubiere escrito. Haga también lista de las personas a quien a de escribir cada ordinario, porque desta manera no incurrirá en error de memoria.

En las cartas que se hubieren de mostrar a otros no escriba negozio o aviso o otra cosa que no sea de mostrar. Las cartas que contubieren diversas cosas se escriban distintamente por capítulos y no escritura continuada. Tenga escritas las cartas, mas no las cierre hasta que se despache el correo porque así no amontonará materia de escribir y podrá añadir quando combenga ${ }^{44}$.

La consumación de ese modelo la hallamos en aquellas cartas donde la página y el texto establecen una disposición armónica cuya solemnidad gráfica refuerza el aspecto figurativo de la escritura, susceptible de ser valorado en sí y por sí mismo ${ }^{45}$. Entre ellas, la que se reproduce del licenciado Pascal a Carlos I (Reyes, 2-V-1549) [Fig. 2] ${ }^{46}$; una del secretario Francisco de Eraso a don García de Toledo, virrey y capitán general en Cataluña (Bruselas, 7-IV-1559) ${ }^{47}$; y otra de

42 Guevara, Antonio de: Epístolas familiares, Amberes, Martín Nucio, [1544], f. 35r. Sobre el epistolario guevariano, REDONDO, Augustin: «El arte epistolar de Fray Antonio de Guevara: del Marco Aurelio a las Epístolas familiares", en Fray Antonio de Guevara y la cultura del Renacimiento en Galicia, Lugo, Diputación Provincial, 1993, pp. 93-114.

43 TORQuemadA, Antonio de: Manual de escribientes, op. cit., p. 37.

44 Véase en BOUZA, Fernando: Imagen y propaganda. Capitulos de historia cultural del reinado de Felipe II, Madrid, Akal, 1998, pp. 235-236.

45 PetruCCI, Armando: «Escritura como invención, escritura como expresión», en su libro $\mathrm{Al}$ fabetismo, escritura, sociedad, Barcelona, Gedisa, 1999, pp. 171-180.

46 AHN, Diversos-Colecciones, 23, núm. 28.

47 AHN, Diversos-General, 73-1 (6). 


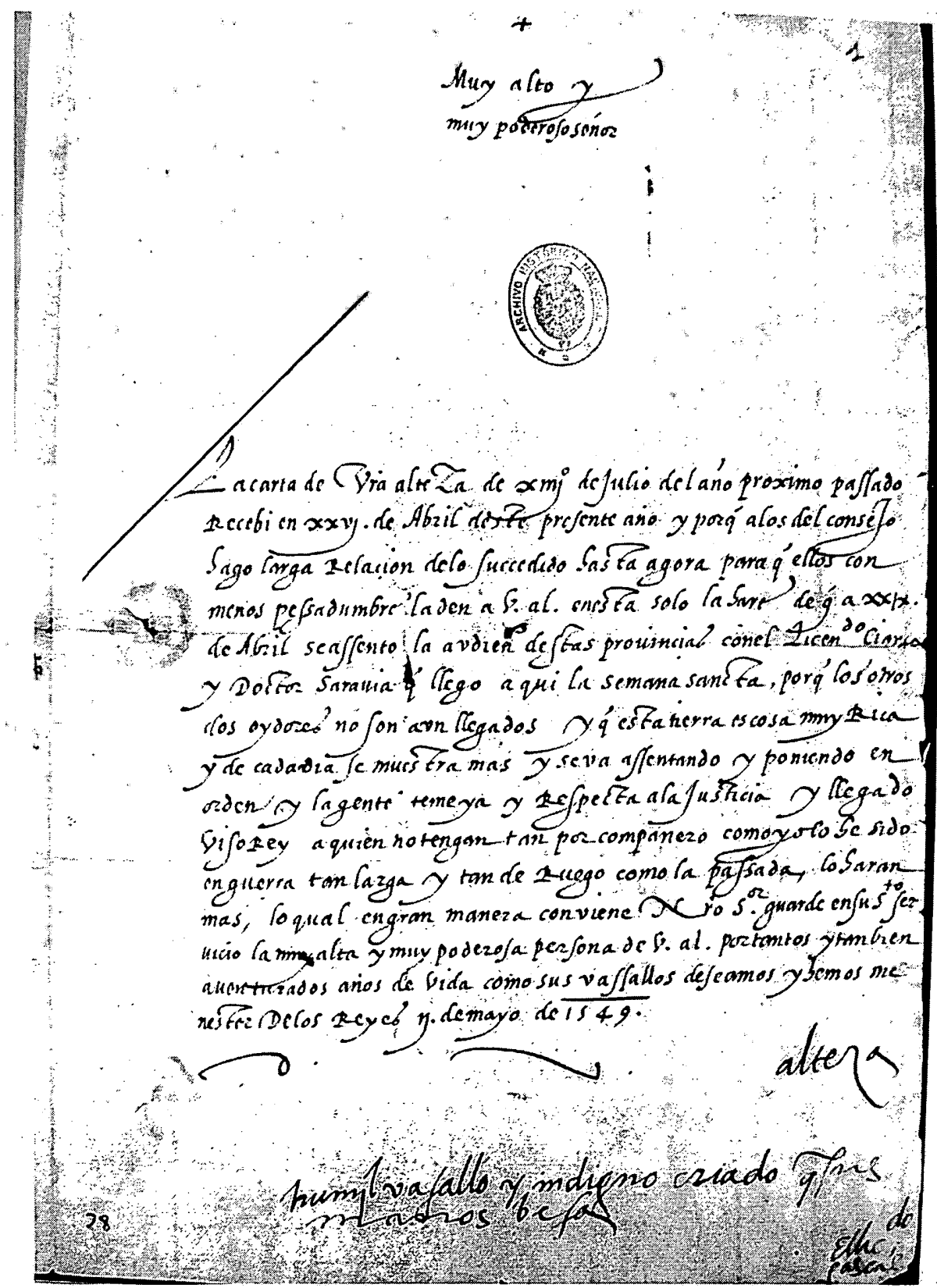

Fig. 2. Carta del licenciado Pascal a Carlos I (Reyes, 2-V-1549). AHN, DiversosColecciones, 23, núm. 28, fol. 1r. 
Carlos I a Juan de la Cerda (Ratisbona, 27-II-1541) ${ }^{48}$. En ésta, la distinción real se exhibe conjugando la cuidada humanística cursiva del secretario con la suscripción hológrafa del soberano; así como por medio del encuadramiento centrado del texto y su equilibrada distribución, la regularidad de las líneas y la visibilidad proveída por la armoniosa administración de los espacios blancos. Si a esto se suma la eventual elección de una escritura propiamente caligráfica, aún es más evidente la proximidad que se puede establecer entre esta clase de cartas y la solemnidad propia de aquellos escritos donde la construcción visual del documento era una manera de simbolizar el poder y el estatus ${ }^{49}$. En esas cartas, además del aspecto gráfico, debía cuidarse el estilo epistolar, donde también estaba depositada la capacidad evocativa apuntada por António Vieira. Como expuso Saavedra Fajardo, tratando de los secretarios, no sólo era cuestión de «pintar las letras» sino que hacía falta desarrollar un trabajo más amplio que incluyera la consulta, disposición y perfeccionamiento de las materias:

Del entendimiento, no de la pluma, es el oficio del secretario. Si fuese de pintar las letras, serían buenos secretarios los impresores. A él toca consultar, disponer y perficionar las materias. Es una mano de la voluntad del príncipe y un instrumento de su gobierno; un índice por quien señala sus resoluciones $[\ldots .$.$] so.$

Obviamente este modus operandi podía presentar diversas ejecuciones formales, ya fuera por la condición de la persona que escribe, por el momento en que se redactaba la carta o por la particular tipología de éstas. De hecho es bastante común que los márgenes no siempre respeten los blancos recomendados en los tratados epistolares o que la escritura sature la página del folio ${ }^{51}$. Todo dependía de los motivos concretos de cada carta, de tal manera que el acomodo a ese orden epistolar guardaba mucha relación con la búsqueda de cierta distinción o con la solicitud de alguna merced. Así las encaminadas a los poderosos y las súplicas solían ser las más cercanas al modelo. Alcanzar la gracia demandada requería asumir la subordinación social y jurídica del peticionario y hacerla explícita en el lenguaje empleado y en la estructura del discurso epistolar, arti-

48 Reproducida y transcrita en Romero TALLAFigo, Manuel; RodríGUEZ LIÁÑEZ, Laureano; \& SÁNCHEZ GonZÁlez, Antonio: Arte de leer escrituras antiguas. Paleografía de lectura, Huelva, Universidad de Huelva, 1995, lámina 62.

49 Sobre estos, véase DOCAMPO, Javier: «Arte para una sociedad estamental: la iluminación de documentos en la España de los Austrias», en El documento pintado. Cinco siglos de arte en manuscritos, Madrid, Ministerio de Educación y Cultura-Museo Nacional del Prado-AFEDA, 2000, pp. 45-66.

so SAavedra Fajardo, Diego: Empresas politicas [1640], ed. de Francisco Javier Díez de Revenga, Barcelona, Planeta, 1988, empresa 56, p. 381.

51 Aunque los testimonios son numerosos, cito a título de muestra un par de ellos: por lo que atañe al dominio oficial, una carta de Juan de Vega a Felipe II (Mesina, 16-VIII-1556; BFZ, Altamira, 154, D2); y de carácter privado, otra de la beata María Bautista a su hermano Pedro García, doctor en Medicina, escrita desde la cárcel (Toledo, 30-V-[1639]; AHN, Inquisición, leg. 102, exp. 2 , fol. 67). 
culado en dos partes separadas por el verbo de súplica ${ }^{52}$. Debido a esto no es raro que muchas cartas de petición fueran preparadas y redactadas por profesionales de la escritura.

La escritura hológrafa exaltaba la relación entre los corresponsales personalizando cada testimonio epistolar. La letra asumía la representación de la persona y se hacía transmisora del respeto, la consideración y el afecto dispensado al destinatario. Doña Leonor Maldonado lo hizo notar al identificar las cartas de su hermana doña Isabel, emigrante en Mérida (Nueva España), alegando que «conoçe muy bien la letra e firma» por cuanto la había visto escribir y firmar en otras circunstancias $^{53}$. A su vez, Felipe II agradeció el carácter hológrafo de una carta de su hija doña Catalina porque así pudo percibir la mejoría en su estado de salud: «Muy bien hicisteis en escribirme, pues los doctores os dieron licencia para ello, porque me quitó mucho cuidado ver carta vuestra y de tan buena letra que no se parecía en ella el mal» ${ }^{4}$. Por lo mismo, el hecho contrario, esto es, no reconocer la letra de una carta, podía despertar alguna intranquilidad. A fin de cuentas, lo que le sucedió a doña Urraca respecto a una de su marido Pedro Álvarez de Sotomayor:

ame puesto vuestra merced en la mayor alteraçión del mundo quando vino el moço del marqués, que me traxo una carta que la letra della yo no la conosçía ni la firma se paresçía con la vuestras5.

En ese sentido, la holografía afianzaba la privacidad del intercambio epistolar, lo que explica la reiterada desconfianza hacia los mediadores gráficos. Al celebérrimo testimonio literario de Teresa Panza, siempre recelosa de poner sus cartas en las manos del bachiller o del cura $^{56}$, pueden agregarse otros de carne

\footnotetext{
$5 \dot{2}$ Así puede verse en distintas peticiones del dominico Juan Vargas Machuca, reo de la Inquisición de Perú en la ciudad de Reyes, al rey y al Inquisidor General. AHN, Inquisición, leg. 16471, exp. 6, núm. 4. De esta tipología epistolar me he ocupado también en CASTILlo GómEZ, Antonio: «Escrito en prisión. Las escrituras carcelarias en los siglos XVI y XVII», art. cit., pp. 154-157. Para mayor abundamiento, me remito a las contribuciones incluidas en NUBOLA, Cecilia \& WÜRGLER, Andreas (ed.), Suppliche e "gravamina». Politica, amministrazione, giustizia in Europa (secoli XIV-XVIII), Bolonia, Il Mulino, 2002; así como al artículo de REPETTI, Paola: «Scrivere ai potenti. Suppliche e memoriali a Parma (secoli XVI-XVIII)", en Alfred Messerli \& Roger Chartier (eds.), Lesen und Schreiben in Europa 1500-1900. Vergleichende Perspektiven. Perspectives comparées. Perspettive comparate, Basilea, Schwabe \& Co. AG- Verlag, 2000, pp. 401-428.

53 LÓPEZ BENITO, Clara Isabel: «La cosmovisión de una mujer salmantina emigrada a las Indias, y vinculada con los Montejo de Yucatán, a través de sus cartas privadas», Salamanca. Revista de Estudios (Salamanca), 44 (2000), p. 321, nota 6.

54 Carta de Felipe II a la infanta doña Catalina, su hija (Santarem, 5-VI-1581). Cfr. BouZA, Fernando (ed.): Cartas de Felipe Il a sus hijas, Madrid, Akal, 1998, p. 42.

55 Rodríguez SuÁrez, $M^{\text {a }}$. del Pilar \& VÁzQuez BerTomeU, Mercedes: «Usos epistolares de la nobleza gallega a principios del siglo XVI: el ejemplo de D. Pedro Álvarez de Sotomayor», en Carlos Sáez \& Antonio Castillo Gómez (eds.), La correspondencia en la bistoria, op. cit., 2002, p. 243.

56 Cervantes, Miguel de: Don Quijote de la Mancha, edición del Instituto Cervantes 1605 2005 dirigida por Francisco Rico, Barcelona, Galaxia Gutenberg-Círculo de Lectores-Centro para la
} 
menos imaginaria. La sevillana María de los Reyes era consciente de la coincidencia de dicha circunstancia en el contenido de las cartas que dirigió a su marido el marinero Francisco Riberos, emigrante en Veracruz: «Que como otro me escribe supiera yo escribir, os enviara decir todo lo que siento en $\mathrm{mi}$ almà ${ }^{57}$. Frente a esto, la precisa observación esta «letra es de mi mano» ${ }^{58}$, que podemos notar en algunas cartas, expresaría la satisfacción por haber conquistado una cierta competencia alfabética y por no tener que depender del oficio de ningún intermediario.

En el ámbito de las correspondencias cortesanas y diplomáticas, la escritura hológrafa, tanto si afectaba a toda la carta o a una parte de la misma, "constituía un signo de deferencia en el cuidado lenguaje de corte, donde el número de líneas escritas de propia mano permitía valorar la estimación que a un corresponsal le merecía su destinatario" ${ }^{59}$. En una carta del arzobispo de Sevilla don Diego de Deza y Tavera a don Pedro Fernández de Córdoba, primer marqués de Priego, escrita entre 1512 y 1515 , puede apreciarse la distinción entre la parte que redacta el secretario, escrita en una letra de transición góticohumanística, y la que corresponde al prelado, en itálica usual ${ }^{60}$. En otros casos, la intervención hológrafa testimonia una forma de gobierno apegada a la escritura y expresada por medio de anotaciones manuscritas, como las muchas que pueden observarse en la correspondencia diplomática de Felipe II: «Está muy bien todo lo que en esto dezís», «ya me lo dixo Çayas», escribe de su puño y letra en el margen de una misiva del 9 de marzo de $1579^{61}$. Se sumaba a esto la confidencialidad de buena parte de la información política y diplomática

Edición de los Clásicos Españoles, 2004, Segunda Parte, cap. L. Con mayor detalle me ocupo de estos pasajes en CASTILlo GómEZ, Antonio: «La escritura representada. Imágenes de lo escrito en la obra de Cervantes", en Antonio Bernat Vistarini (ed.), Volver a Cervantes, Actas del IV Congreso Internacional de la Asociación de Cervantistas (Lepanto, 1/8 de octubre de 2000), tomo I, Palma de Mallorca, Universitat de les Illes Balears, 2001, pp. 313-316; y "Aunque sean los papeles rotos de las calles". Cultura escrita y sociedad en El Quijote», Revista de Educación (Madrid), número extraordinario «El Quijote y la educación», (2004), pp. 70 y 73-74.

57 Carta de María de los Reyes a su marido Francisco Riberos (1617). AGN, Inquisición, vol. 325, s. fol. Cfr. SÁNCHEZ RUBIO, Rocío \& TESTÓN NúÑEZ, Isabel: El bilo que une. Las relaciones epistolares en el Viejo y el Nuevo Mundo (Siglos XVI-XVIII), Cáceres, Universidad de Extremadura; Mérida, Editora Regional de Extremadura, 1999, p. 294.

58 Ibidem, p. 32.

59 BouzA, Fernando: Corre manuscrito. Una bistoria cultural del Siglo de Oro, Madrid, Marcial Pons, 2001, p. 138.

60 Romero TAllafigo, Manuel; Rodríguez LiáñeZ, Laureano; \& SÁNCHEZ GonZÁlez, Antonio: Arte de leer escrituras antiguas, op. cit., lámina 54. En esta misma obra se reproduce y transcribe otra carta en letra humanística de don Gonzalo Fernández de Córdoba, "el Gran Capitán», a su sobrino don Pedro (c. 1513), que corrobora lo dicho.

61 BFZ, Altamira 155, D69. Sobre el «rey papelero» y su obsesiva escritofilia, BouZA ÁlvAREZ, Fernando J. «La majestad de Felipe II. Construcción del mito real», en José Martínez Millán (dir.), La corte de Felipe II, Madrid, Alianza, 1994, pp. 58-72; y, más ampliamente, Escudero, José Antonio: Felipe II: el rey en el despacho, Madrid, Editorial Complutense, 2002. 
transmitida por vía epistolar, de ahí que dicha correspondencia hiciera uso de complejos sistemas de cifrado al punto de requerir que algunas cartas fueran acompañadas de abecedarios y de otras misivas con las claves imprescindibles para el desciframiento ${ }^{62}$. Entre los varios procedimientos empleados, uno de los más habituales consistía en desplazar o mezclar los caracteres del texto siguiendo las reglas pactadas por los corresponsales; mientras que otras veces se valieron de la combinación de letras y símbolos o del valor numérico asignado a cada letra ${ }^{63}$. Una variedad de la que el mismo Luis de Zapata dio cuenta en su Miscelánea (c. 1593):

De cifras hay muchas maneras, y puede haber tantas cuantas de pescados hay en la mar. Unos mudan las vocales; otros las consonantes; otros las trastuecan todas; otros ponen letras impertinentes que a cada tercer o cuarto asiento no valen nada, sino para escurecer y hacer que nazcan más dificultades; otros ponen nuevos caracteres; otros letras que con sólo agua se pueden leer; otros escritos con sebo que se lean poniendo encima papel quemado; otros que se vayan leyendo los renglones al revés; otros que se lea por la espalda; otros de abajo arriba; otros de arriba abajo; otros con çumo de limón o de naranja, que no se pueden leer hasta ponerse al fuego o calentarse mucho con el sol; otros que las primeras letras de los renglones hablen; otros que las postreras; otros que a tercera o cuarta o quinta casa; otros haciendo por otro papel ventanas, y que solas las letras que salieren por las ventanas valgan o no valgan: cosa en la guerra, en negocios grandes utilísima y necesaria, porque si vienen a poder de enemigos las cartas videntes non videant, et audientes non intelligant; pero de todas es menester que a quien se envian tengan el abecedario 64 .

\section{LENGUAS Y ESCRITURAS}

Cifras aparte, ¿cuáles eran las lenguas de la comunicación epistolar hispana en el Siglo de Oro y cuál su relación con la persona y el evento de escritura? Sin lugar a dudas, la lengua por excelencia fue el castellano debido al peso de este viejo reino en la construcción política y administrativa del Imperio. No obstante, en el caso de las relaciones diplomáticas la amplitud territorial requirió con frecuencia del latín como lengua franca, según puso de manifiesto Saavedra Fajardo al tratar sobre las condiciones que debía reunir un buen secretario:

62 VIAUD, Aude: «La correspondance diplomatique au XVI ${ }^{\mathrm{e}}$ siècle», Arquivos do Centro Cultural Calouste Gulbenkian (Lisboa), XLI (2001), pp. 62-63.

63 ALlAIRE, Bernard: "Le décodage de la correspondance chiffrée des diplomates espagnols au $\mathrm{XVI}^{\mathrm{e}}$ siècle», en Pierre Albert (ed.), Correspondre, jadis et naguère, $120^{\mathrm{c}}$ Congrès National des Sociétés Historiques et Scientifiques: Section Histoire Moderne et Contemporaine (Aix-en-Provence, 1995), París, Comité des Travaux Historiques et Scientifiques, 1997, pp. 207-218.

64 Zapata, Luis de: Miscelánea, Madrid, Imprenta Nacional, 1959 (Memorial Histórico Español, XI), pp. 456-457.

Hispania, LXV/3, núm. 221 (2005) 847-876 
No parece que quiso el rey don Alonso que solamente supiese el secretario escribir la lengua latina, sino también hablalla, siendo tan importante a quien ha de tratar con todas las naciones. En estos tiempos que la monarquía española se ha dilatado por provincias y reinos extranjeros es muy necesario, siendo frecuente la correspondencia de cartas latinas ${ }^{65}$.

Por otro lado, su pervivencia lingüística se produjo especialmente en determinados ámbitos de la Iglesia, máxime en la correspondencia dirigida al Pontífice y a otros altos representantes eclesiásticos; así como en los intercambios de la república literaria, según dejan ver, entre otros, los epistolarios de Francisco de Enzinas y de Hernán Núñez de Guzmán ${ }^{66}$. Distinta es la adopción puntual del latín en encabezamientos y despedidas o en las citas y lugares comunes, mayormente de procedencia bíblica, introducidos en numerosas cartas.

Al lado del latín debe estimarse el uso de otras lenguas en las relaciones con los distintos estados de la época. Tal circunstancia destaca la relevante función desempeñada por los diferentes intermediarios y, en especial, por los traductores. Dicha importancia se ha podido constatar, por ejemplo, en la correspondencia diplomática entre España y Marruecos durante el último tercio del siglo XVI y los primeros años del XVII, donde fue bastante habitual que las cartas se redactaran en castellano y que el sultán las validara en árabe, sirviéndose para ello de personas conocidas y de otras que no lo eran, hebreos, moriscos expulsados y cautivos. En una misiva del duque de Medina Sidonia a Felipe III (1605), el primero señaló como novedoso que las cartas del jerife Muley Buferes incluyeran la versión traducida:

Acava de llegar Alonso Marín de Marruecos por la vía de Safy en un navío inglés [...] y con él me responde el xerife Muley Buferes la carta original que es con ésta y dentro della benía traducida, cossa nueva y no ussada entre estos xerifes por la correspondençia que yo he tenido con hellos ${ }^{67}$.

Otras situaciones de bilingüismo gráfico emanan de la pluralidad de las lenguas habladas y escritas en el mundo hispano. Así, en la correspondencia de Pedro Álvarez de Sotomayor, aunque pocas, se incluyen algunas misivas en gallego, si bien son más numerosas las cartas en castellano con algunas expresiones y estructuras gramaticales gallegas. Por lo mismo, en los dominios americanos circulaban cartas escritas total o parcialmente en las lenguas indígenas, sobre

65 SAAVEDRA FAJARDO, Diego: Empresas políticas, op. cit., empresa 56, p. 384

66 EnZINAS, Francisco de: Epistolario, ed. de Ignacio J. García Pinilla, Ginebra, Droz, 1995; y Signes Codoñer, Juan; Codoñer Merino, Carmen; Domingo MAlvadí, Arantxa: Biblioteca y epistolario de Hernán Núñez de Guzmán (El Pinciano): una aproximación al bumanismo español del siglo XVI, Madrid, CSIC, 2001.

67. AGS, Estado, leg. 200. Citado en GARCía-Arenal, Mercedes; RodríGuEZ MEdiano, Fernando; EL Hour, Rachid: Cartas marruecas. Documentos de Marruecos en archivos españoles (siglos XVI-XVII), Madrid, CSIC, 2002, p. 17, nota 1; y pp. 17-45, para el cometido e identidad de los traductores. 
todo en la correspondencia interna pero también en la dirigida por los caciques locales al virrey o al monarca español. Junto a esto deben contemplarse las peculiaridades idiomáticas de cada lugar de origen, reflejo de la interacción entre lo hablado y escrito que puede observarse en numerosas cartas, máxime si son privadas $^{68}$. Al igual que se ha señalado de otros documentos ${ }^{69}$, en las cartas de los emigrantes andaluces y en las de los habitantes de Nueva España es bastante común el seseo, la confusión de las consonantes líquidas $/ 1 /$ y /r/ cuando preceden a otra o la pérdida del fonema sonoro/d/ en posición intervocálica.

Abundando ahora en el estudio de la carta en cuanto expresión de la cultura escrita de un tiempo determinado, es evidente que su materialidad entraña un testimonio impagable tanto de la competencia alfabética de quien escribe y de su distribución en el seno de una sociedad como de la intensidad del hábito. El crecimiento de la alfabetización y la pluralidad de las vías de acceso a la escritura en los siglos XVI y XVII dieron lugar a una realidad gráfica muy variada, sobre todo en el terreno de las escrituras personales. En la mayoría de los casos resulta difícil adscribirlas con certeza a un determinado tipo gráfico, siendo por el contrario el reflejo más claro del dinamismo inherente al fenómeno escriturario y de la consiguiente limitación de las nomenclaturas paleográficas a la hora designar los distintos grados de apropiación.

Si nos fijamos primeramente en las cartas redactadas por algunos humanistas y gentes de letras, es frecuente que las mismas muestren una mise en page distribuida en tres espacios que corresponden a otras tantas partes del orden epistolar: el proemio, el discurso y el fin, o, al decir de Tesauro, la cabeza, el cuerpo y la cola o remate ${ }^{70}$. La escritura utilizada se adscribe normalmente a la humanística cursiva, en algunos testimonios con distintos signos de influencia gótica, bien sea cortesana en los albores del siglo XVI o procesal en las fases más avanzadas. Si tomamos en consideración sendas misivas de Arias Montano al licenciado Juan de Grial, fechadas respectivamente el 5 de febrero de 1581 y 1 de diciembre de 1583 [Fig. 3] $]^{71}$, o bien otras de los músicos Francisco Guerrero y Tomás Luis de Victoria al deán y cabildo de la catedral de Jaén ${ }^{72}$, se constatan los siguientes aspectos: de un lado, la letra empleada corresponde a una humanística cursiva de tipo cancilleresco de módulo comprimido, inclinada

\footnotetext{
68 A propósito de este asunto, DE BLASI, Nicola: Tra scritto e parlato. Venti lettere mercantili meridionali e toscane nel primo Quattrocento, Nápoles, Liguori, 1982, y, del mismo, «Fonti scritte quattrocentesche di lingua parlata: problemi di metodo (con una lettera inedita)», en G. Holtus \& E. Radtke (eds.), Gesprochene Italienisch in Geschichte und Gegenwart, Tübingen, G. Narr, 1985, pp: 340-353.

69 EBERENZ, Rolf; DE LA TORRE, Mariela: Conversaciones estrechamente vigiladas. Interacción coloquial y español oral en las actas inquisitoriales de los siglos XV a XVII, Zaragoza, Pórtico, 2003, pp. 113-114.

70 TeSAURo, Emanuele: Arte de cartas misivas, op. cit., pp. 12-15 y 20.

71 IAN/TT, Casa Cadaval, liv. 18, fols. 27-30.

72 Transcritas y reproducidas en la obra Imprentas y librerías en el Jaén renacentista, Catálogo de la exposición (Jaén, Palacio de Villardompardo, 11 noviembre-4 diciembre 2002), Jaén, Instituto de Estudios Gienenses, 2002, pp. 174-181.
}

Hispania, LXV/3, núm. 221 (2005) 847-876 


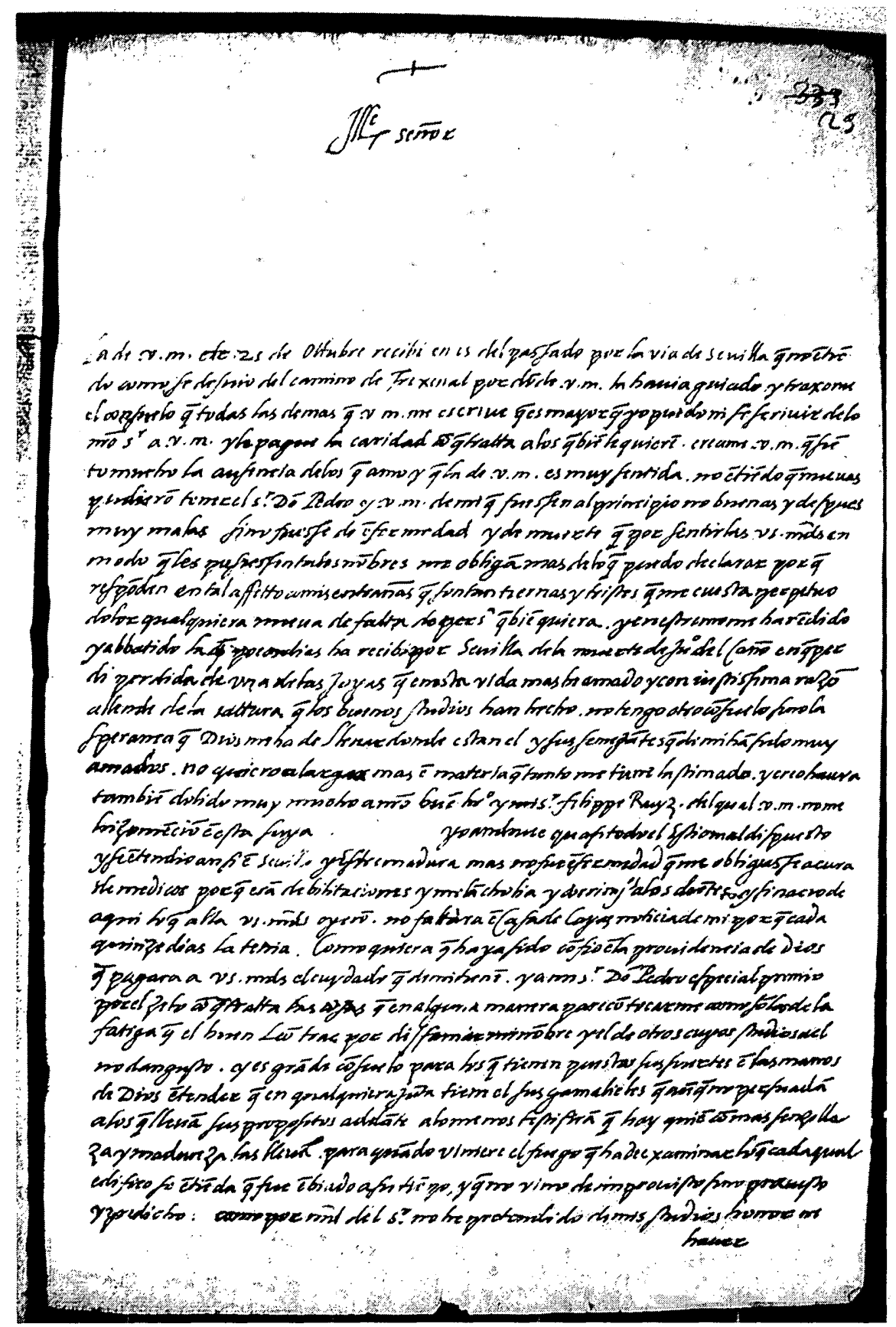

Fig. 3. Carta de Benito Arias Montano al licenciado Juan de Grial (La Peña de Aracena, 1-XII-1583). IAN/TT, Casa Cadaval, liv. 18, fol. 29. 
a la derecha y muy ligada; y de otro, la regularidad y equilibrio de la mise en texte. En lo que concierne a otros pormenores lingüísticos debe señalarse el uso variado de los signos de puntuación, ya sea para indicar las abreviaturas (av. $s^{0}$, a vuestro señor), en posición de distinctio finalis o marcando las pausas respiratorias y orales; el empleo regular de las abreviaturas, unas veces por contracción (Fran, Francisco; por $q$, por que) y otras por medio de letras sobrepuestas $\left(s^{\circ}\right.$, señor); la utilización de la enclisis (suplícolos) y de la proclisis (lesirva); o las mayúsculas para nombres propios y para distinguir fonéticamente la /r/ vibrante (Recopilado, Racionero, Reciba). Así mismo, las cartas de Luis Vives, amén de la elegante humanística, dejan ver el uso reiterado de signos de puntuación y de abreviaturas, la destreza del rasgo gráfico, los nexos y ligaduras de las letras o el recurso a las mayúsculas para estructurar el discurso ${ }^{73}$. En suma, una serie de aspectos que son comunes a los escritos de otras personas de similar condición y que también pueden apreciarse en varias misivas del futuro obispo de Osuna Sebastián Pérez al licenciado Juan Grial fechadas en distintos momentos de 1582. En éstas la competencia escrituraria se manifiesta tanto en la composición general del texto como en la suficiencia lingüística que apuntan la separación de las palabras y el óptimo empleo de distintos recursos ortográficos ${ }^{74}$.

En el extremo opuesto a estos testimonios, otros explicitan la impericia de quien escribe y la discontinuidad del hábito. Tales cartas corresponden al nivel de las escrituras inexpertas y se caracterizan por el exagerado módulo de la letra hasta tal punto que muchas veces parece más dibujada que propiamente escrita $^{75}$. En ellas, las constantes interacciones de la lengua coloquial, el uso limitado de signos ortográficos y de otras abreviaturas que no sean la conjunción que, la separación silábica de las palabras y las uniones irregulares de éstas son señales inequívocas de la génesis oral del texto escrito y de su dictado interior. Igualmente es harto común el empleo inseguro de las mayúsculas, que podría

73 Sirve de referencia una carta suya, fechada en Ámberes a 6 de septiembre de 1535, reproducida y comentada en Riesco TERrERo, Ángel; Ruiz García, Elisa; DOMínguez APARICIO, Jesús; SÁnChez Prieto, Ana Belén: Aproximación a la cultura escrita. Material de apoyo, Madrid, Playor, 1995, pp. 81 (lámina) y 191-192 (comentario paleográfico y diplomático).

74 IAN/TT, Casa Cadaval, liv. 18, fols. 103-108.

75 Los rasgos característicos de las «escrituras inexpertas" han merecido consideraciones propias según que el enfoque adoptado sea paleográfico o linguístico. Respecto al primero es obligada la referencia a PETRUCCI, Armando: «Scrittura, alfabetismo ed educazione grafica nella Roma del primo Cinqucento: da un libretto di conti di Maddalena pizzicarola in Trastevere", Scrittura e civiltà (Roma), 2 (1978), pp. 167-188, y La ciencia de la escritura, op. cit, cap. 2, «Escribir y no", pp. 27-40. Para la perspectiva lingüística remito a los trabajos de BLANCHE-BENVENISTE, Claire, "Les unités: langue écrite, langue orale», en Clotilde Pontecorvo \& Claire Blanche-Benveniste (eds.), Proccedings of the Workshop on Orality versus Literacy: Concepts, Metbods and Data. Siena, Italy, 24-26 September 1992, Estrasburgo, European Science Foundation, 1993, pp. 133-194, e Idem: Estudios lingüísticos sobre la relación entre oralidad y escritura, Barcelona, Gedisa, 1998; así como a la obra de MARQUILHAS, Rita: A Faculdade das Letras. Leitura e escrita em Portugal no séc. XVII, Lisboa: Imprensa Nacional-Casa da Moeda, 2000, pp. 229-266.

Hispania, LXV/3, núm. 221 (2005) 847-876 
entenderse como una marca de pronunciación y no sólo como una muestra de incompetencia alfabética, y la dislocación gráfica de algunos fonemas, sobre todo las consonantes líquidas $/ \mathrm{l} / \mathrm{y} / \mathrm{r} /$. Si nos fijamos, por ejemplo, en las cartas de Andrés de Cepeda Negrete a su primera mujer Isabel Álvarez, la experiencia penosa de la escritura se atisba en el trazo inclinado de la letra y en su incapacidad a la hora de respetar el pautado mental; y, más allá de esto, en la sustitución del fonema /c/ por /q/ (esqrebir), en la irregular separación de las palabras, con numerosas incorrecciones en las uniones y desuniones (Madr-id, ma-ntel), o en la continuidad del texto, esto es, sin ninguna jerarquía de temas e informaciones y falto de cualquier elemento que contribuya a su organización interna [fig. 4$]^{76}$. Estas particularidades son similares a las que podemos observar en una carta de Lázaro García a Manuel Becerra, fechada en julio de 1645, cuya escritura apunta a una actividad inhabitual y fatigosa, como suele acontecer en los sectores menos alfabetizados. En ella es notoria tanto la nula puntuación del texto como la separación anómala de las palabras o las reiteradas alteraciones fonéticas. Respecto a éstas nótese también la sustitución del fonema /c/ por /q/ (qonosi o quristobal) o la dislocación de /r/ en posición post-vocálica (Gaspra por Gaspar) [Fig. 5]77.

Fuera de las dificultades concretas derivadas de alguna limitación física, dichos rasgos pueden señalar deficiencias en el proceso de aprendizaje de la escritura o una práctica inhabitual de la misma, ya fuera porque no se tenía interiorizada la necesidad de escribir, porque se anteponían otras circunstancias o porque se disponía de un secretario. Así se pueden entender los distintos grados de dominio gráfico apreciables en las cartas y billetes de Miguel de Piedrola y Beaumont según los escribiera él o su secretario:

El secretario está estudiando en el Colejio de los Teatinos y por esta causa escribo la rreplica, de la letra que no $\mathrm{m}\langle\mathrm{e}\rangle$ ensenen de los maestros ordinarios, por ser notorio deber a Dios esta graçia con las demás y es que nunca tube maestro que me dijese palabra, jamás, y de sólo saber las letras ordinarias me persuadió el fuego del coraçón, que me fuese mostrando a escrebir, y en esto no digo menos berdad de la que a principiado a esperimentar v. md. ${ }^{78}$.

Un testimonio que invalida cualquier tentación de asociar sin más los niveles de habilidad gráfica a la condición social nos lo proporciona una carta de Carlos II a don Juan Francisco de la Cerda Enríquez de la Ribera, octavo duque de Medinaceli (Madrid, 21-II-1678). En ella, el exagerado módulo de la letra,

76 AHN, Inquisición, leg. 23, exp. 1, s. fols. El expediente incluye dos cartas, una fechada en Granada a 16 de junio de 1570 y la otra sin data pero escrita por entonces.

77 AGN, Inquisicion, vol. 463, exp. 3, fol. 43r. Según ha señalado MarQuilHas, Rita: $A$ Faculdade das Letras, op. cit., pp. 245-248, el mismo fenómeno puede observarse en los testimonios portugueses.

78 AHN, Inquisición, Consejo, leg. $3712^{3}$, núm. 2, 6a pieza, núm. 8 , s. fol. 


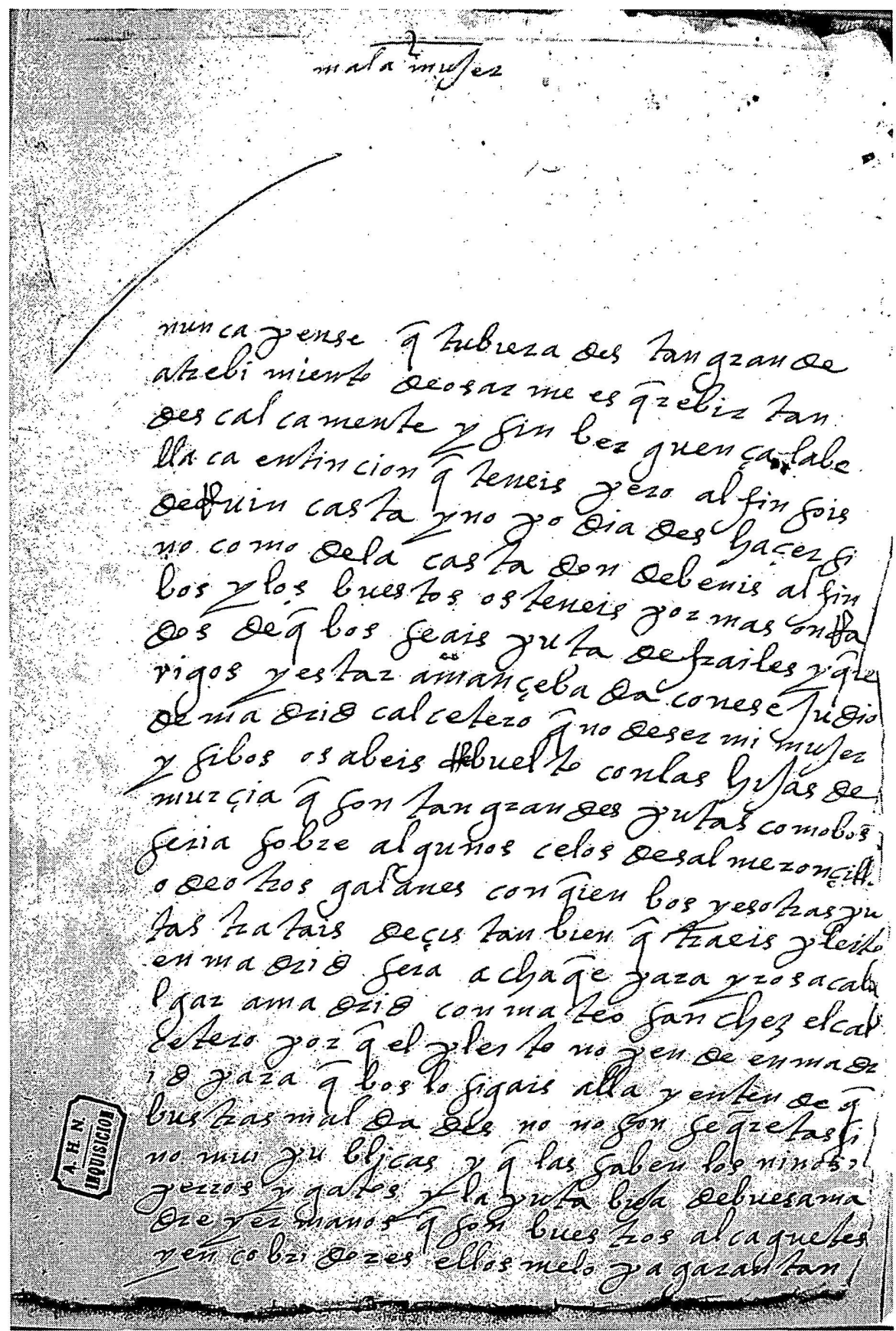

Fig. 4. Carta de Andrés de Cepeda Negrete a su primera mujer Isabel Álvarez [Granada, después de 16-VI-1570]. AHN, Inquisición, leg. 23, exp. 1, s. fol.

Hispania, LXV/3, núm. 221 (2005) 847-876 


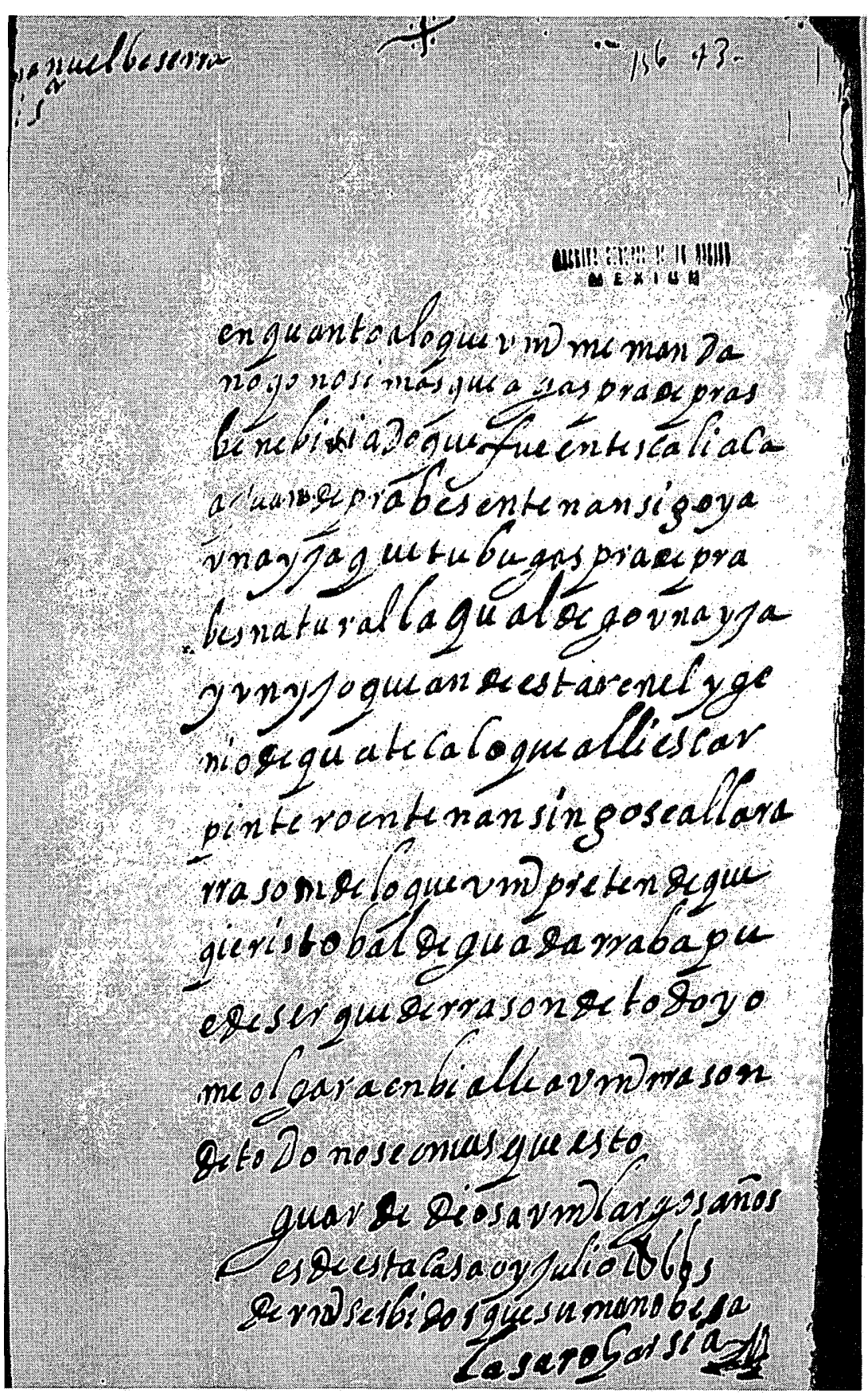

Fig. 5. Carta de Lázaro García a Manuel Becerra (julio 1645). AGN, Inquisición, vol. 463, exp. 3, fol. 43 r. 
la separación de ésta, la irregular ruptura de ciertas palabras (prime-r, linea 6; ma-ndado, linea 10) o algunos errores ortográficos (olvido del fonema $/ 1 /$ en el artículo $\mathrm{el}$, línea 3) señalan inequívocamente la impericia gráfica de un rey conocido por su incapacidad mental y que a la edad de nueve años aún no sabía leer y escribir ${ }^{79}$.

Las cartas, en suma, son el reflejo de la pluralidad gráfica inherente a los distintos niveles de apropiación y de las interpretaciones escriturarias desarrolladas por cada individuo. Esta circunstancia se manifiesta especialmente en la variedad que presentan las escrituras usuales y la imposibilidad de insertarlas en categorías cerradas. Muestra de ello la podemos hallar en muchos testimonios epistolares de los emigrantes a Indias, entre otros en las cartas de Bartolomé Flórez, Pedro Martín, Diego Martín y doña María de Esquivel y Castañe$\mathrm{da}$, si bien la de ésta denota una sustancial diferencia entre la signatura hológrafa y el resto, escrito por otra mano ${ }^{80}$. Pero esto no significa que debamos omitir la repercusión de las condiciones sociales en el acceso a la escritura y, a la postre, en el carácter de los testimonios escritos. La reiteración de unos rasgos ortográficos, morfosintácticos y léxicos en los documentos epistolares de la gente común al igual que la «sucesión aparentemente desordenada de infomaciones y expresiones comunicativas yuxtapuestas» ${ }^{81}$, son el exponente más claro de la extrañeza del hábito de escribir y de la desigualdad de los procesos de alfabetización. Éstos, en suma, se vieron afectados por las discriminaciones de clase y por aquellas derivadas del sistema de géneros.

En lo que concierne a las cartas de mujeres no se trata de sostener que todas observaran unas mismas características gráficas, ya que esto sería tanto como pensar en una escritura femenina que diera la espalda a la clase social de pertenencia y a las desigualdades existentes entre ellas, cuando es claro que la alfabetización femenina tuvo otros contenidos y se llevó a cabo en espacios distintos, por lo que su repercusión fue indiscutible y seguramente explica que, a ojos de los contemporáneos, la letra de las mujeres se calificara en términos diferenciados. Doña Mariana de Morguiz refirió en una carta a su padre Juan Rodríguez que las mujeres tenían menos «aparejo para escribir» que los hom-

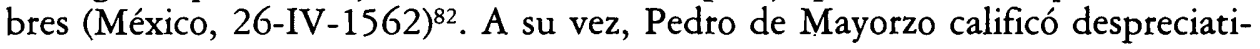

79 Véase una reproducción de la carta en ROMERo TALLAFIGO, Manuel; RODRíGUEZ LIÁÑEZ, Laureano; \& SÁNCHEZ GONZÁlEZ, Antonio: Arte de leer escrituras antiguas, op. cit., lámina 77, quienes la incluyen en el tipo gráfico de la humanística cursiva. Personalmente considero que las características apuntadas la sitúan más bien en el nivel de la escritura inexperta, esto es, la más característica de las personas semialfabetizadas. Una grafía no menos descuidada es la que puede notarse en los testimonios epistolares del príncipe don Carlos, según vemos, a título de ejemplo, en la carta que escribió al comendador mayor Luis de Requesens, embajador en Roma (Madrid, 18-II-1567). IVDJ, E. 38, doc. 40. Debo esta referencia a la amabilidad de Santiago Martínez Hernández.

80 AGI, Indiferente, 2050, núm. 18; 2054, núm. 17; 2050, núm. 21; y 2065, núm. 84.

81 PeTruCCI, Armando: La ciencia de la escritura, op. cit., p. 92.

82 OTTE, Enrique: Cartas privadas de emigrantes a Indias, 1540-1616, Jerez-Cádiz, Junta de Andalucía, Consejería de Cultura-Escuela de Estudios Hispanoamericanos de Sevilla, 1988, núm. 7, p. 43. 
vamente la letra de las mujeres al rogar a su esposa Isabel de Herrera, vecina de Triana, que si quería ir con él, primero se lo debía comunicar por medio de una carta "de buena letra, que no sea de mujer, para que se entienda» (San Juan de Ulúa, 9-II-1594) ${ }^{83}$. Por su parte, Juana Rodríguez Barroso y Francisca de Vergara se disculparon de su mala caligrafía añadiendo que no habían podido remediarlo debido a la falta de escribanos: «Otra carta escribo a bm. que ba de mano de mi sa dona Mençia de Ayala, perdone vm. la letra porque no ay escrivano todas vezes a mano para poder escribir» ${ }^{84}$. De todos modos su trazo no difiere mucho de la procesal empleada contemporáneamente por muchos varones.

Los rasgos gráficos de estas mujeres faltas de aparejo para escribir eran bastante similares a los que hemos comentado al tratar la escritura inexperta, es decir, el módulo grande, la inapropiada separación de las palabras, la continuidad discursiva, la incompetencia ortográfica y el desconocimiento de la "gramática de la legibilidad», entendida como el manejo necesario para asegurar la comprensión del texto. Dichas características, observadas en otro lugar a propósito de sendas cartas de María de Bazán y Catalina de Jesús ${ }^{85}$, se pueden apreciar en algunas de Francisca de Vergara ${ }^{86} \mathrm{o}$ en los billetes de doña Mariana de Vera ${ }^{87}$. Si nos detenemos con más detalle en una carta de Francisca de Vergara a su marido Roque de Santa María (Sevilla, 7-IV-[1604]) es de notar la ausencia de todo trazo de unión entre las letras así como el módulo de éstas y una impericia gráfica que tiende al diseño [Fig. 6]. Aunque su ejecución sea más fluida, la división silábica es una particularidad que también puede verse en una carta de la marquesa de Mondéjar al arzobispo de Granada don Pedro Vaca de Castro (Madrid, 17-IV-1595) ${ }^{88}$. Indudablemente, otros testimonios femeninos -como los epistolarios de Hipòlita Rois, Estefania de Requesens o la emperatriz María de Austria ${ }^{89}$ - acreditan una práctica mucho más regular, según señala la celeridad del trazo, la correcta humanística dextrógira o el conocimiento de las abreviaturas corrientes en la época, fuera de otros competencias ortográficas, morfosintácticas y discursivas equiparables a las cartas mejor escritas.

83 Ibídem, núm. 199, p. 179.

84 AGN, Inquisicion, vol. 368 (2), fol. 589-591. La carta de Juana Rodríguez Barroso en AGN, Inquisición, vol. 184, exp. 11, fol. 254.

8s Remito a mi trabajo «Del tratado a la práctica. La escritura epistolar en la Época Moderna», art. cit., pp. 96-100.

86 AGN, Inquisición, vol. 368 (2), fol. 589.

87 AGN, Inquisición, vol. 486 ( $1^{\mathrm{a}}$ parte), fols. $3-4$ y 29.

88 IAN/TT, Casa Cadaval, liv. 18, fols. 224-225.

89 Para las cartas de las nobles catalanas, véase Epistolaris d'Hipòlita Roís, op. cit., pp. 42-52; y SANMARTí i Roset, Montserrat \& PIÑOL I Alabart, Daniel: «Les dones i l'escriptura (finals del segle XIV al segle XVI)», en Els papers socials de les dones (I), Tarragona, Silva editorial, 2001; pp. 34-25. En cuanto a la emperatriz María de Austria, Galende DíAZ, Juan Carlos \& SalamanCa LÓPEZ, Manuel: Epistolario de la emperatriz Maria de Austria: textos inéditos del Archivo de la Casa de Alba, Madrid, Nuevos escritores, 2004. 


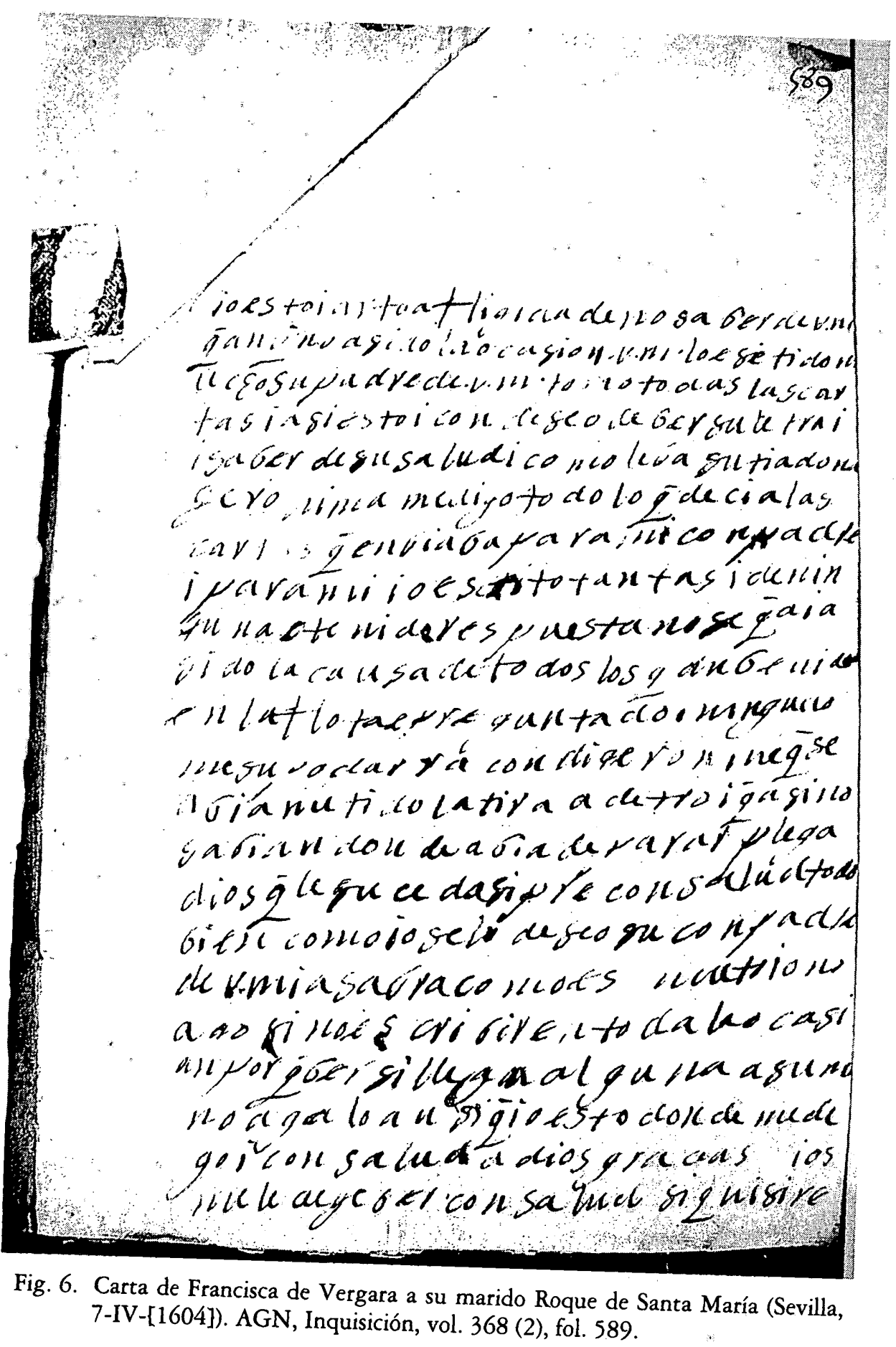

Hispania, LXV/3, núm. 221 (2005) 847-876 
Dicho esto, tampoco es extraño que las cartas privadas respondan a una autoría múltiple reflejo de las distintas personas que intervienen en ellas. De hecho, en las correspondencias familiares no faltan testimonios donde se suceden las manos de distintos hijos o parientes. Estas cartas nos sitúan frente al pluralismo gráfico de un determinado período y, sobre todo, ante una práctica entendida en sentido familiar o comunitario. A la sazón, cartas escritas por varias manos que se prestaban a una lectura compartida y en voz alta, construyendo con ello una cierta comunidad de escritura. Reforzaban estos vínculos los recados y comunicaciones que solían contener así como la lectura sucesiva por distintos corresponsales:

Jo scrich a micer Vallserà, la que serà ab la present; va oberta perqué la lijau, també la mostrareu a mossèn Camós $y$, aprés, cloeu-la y donau-la-y y, com s'acxostuma, deteniu-vos fins que la haja ell legida y notau los senyals que en ell són, e spereu que, per més dissimulat que sia, dirà o mostrarà alguna cosa $[\ldots . .]^{90}$.

Portadora de novedades y recados familiares, embajadora de ideas o mensajera de planes políticos, la carta cobraba todo su protagonismo en las manos de su destinatario. En ese momento, la materialidad de la misma desempeñaba una baza importante a la hora de retratar y representar al emisor. Hacerse visible a través del escrito epistolar requería por ello que se guardara el decoro perseguido por los artes de escribir misivas, cuyo respeto afectaba tanto a los interiores de la carta, es decir, al «estilo, tema, razones, conceptos, modos, términos, títulos y cumplimientos», proporcionados a la persona «a quien se escrive, a la que escrive y al assumpto de que se escrive»91; como a los «exteriores»92, esto es, al formato de la carta, al tipo de letra, a la clase del papel, a la relación entre el texto y la página, a la disposición de la escritura e incluso a la manera de plegarla y sellarla. En suma, a todo cuanto nos informa sobre su constitución material y vincula ésta a la condición social y a la educación gráfica de quien escribe.

90 Carta de Hipòlita Roís a Bernat Capeller (Valencia, 9-III-1535): Epistolaris d'Hipòlita Roís, op. cit., p. 371.

91 TESAURO, Emanuele: Arte de cartas misivas, op. cit., p. 18.

92 LoBo, Francisco Rodrigues: Corte na aldeia (1619), ed. José A. de Freitas Carvalho, Lisboa, Presença, 1992, p. 75. 